\title{
Elevated BMI might more significantly affect the outcome negatively in luminal type breast cancer patients with brain metastases
}

\author{
Kadri Altundag ${ }^{1}$ iD
}

Received: 2 August 2018 / Accepted: 21 August 2018 / Published online: 24 August 2018

○) Springer Science+Business Media, LLC, part of Springer Nature 2018

\section{Dear Editor,}

I want to congratulate McCall and their colleagues for their article [1] in which they investigated prognostic significance of obesity and diabetes in 84 women with brain metastases from breast cancer treated with intracranial radiation therapy. They found that elevated BMI or diabetes may negatively impact both overall survival and local control in patients with brain metastases from breast cancer. However, the authors did not compare prognostic significance of obesity and diabetes with specific molecular subtypes (triple negative vs. luminal type vs. HER2 + disease). One study evaluated the effect of BMI on survival in 5668 early stage breast cancer patients according to tumor subtype, metabolic syndrome, and systemic treatment. They found that BMI $\geq 25 \mathrm{~kg} / \mathrm{m}^{2}$ was an unfavorable survival factor, particularly in patients with luminal type breast cancer [2]. Importantly, immunohistochemical status of brain metastasis was not reported in the current study. A change of estrogen receptor (ER), progesterone receptor (PR), and HER2 status in distant metastases has frequently been reported. Recent metaanalysis including 39 studies assessing receptor conversion from primary breast tumors to paired distant breast cancer metastases showed that negative to positive conversion percentages were $21.5,15.9$, and $9.5 \%$ for ER, PR, and HER2 [3].Taken all together, elevated BMI in current study might more significantly affect the outcome negatively in luminal type breast cancer patients with brain metastases. This issue merits further investigation.

Funding No funding for this paper.

\section{Compliance with ethical standards}

Conflict of interest I have no conflict of interest to declare.

Ethical approval My manuscript complies with the Ethical Rules applicable for this journal.

Research involved in human or animal rights This article does not contain any studies with human participants or animals performed by any of the authors.

\section{References}

1. McCall NS, Simone BA, Mehta M et al (2018) Onco-metabolism: defining the prognostic significance of obesity and diabetes in women with brain metastases from breast cancer. Breast Cancer Res Treat. https://doi.org/10.1007/s10549-018-4880-1

2. Cho WK, Choi DH, Park W et al (2018) Effect of body mass index on survival in breast cancer patients according to subtype, metabolic syndrome, and treatment. Clin Breast Cancer. https:// doi.org/10.1016/j.clbc.2018.04.010

3. Schrijver WAME, Suijkerbuijk KPM, van Gils CH et al (2018) Receptor conversion in distant breast cancer metastases: a systematic review and meta-analysis. J Natl Cancer Inst 110(6):568-580
Kadri Altundag

altundag66@yahoo.com

1 MKA Breast Cancer Clinic, Tepe Prime, Cankaya, 06800 Ankara, Turkey 